\title{
Confluent and reticulated papillomatosis: diagnostic and treatment challenges
}

This article was published in the following Dove Press journal:

Clinical, Cosmetic and Investigational Dermatology

25 August 2016

Number of times this article has been viewed

\author{
Joel Hua-Liang Lim' \\ Hong Liang Tey ${ }^{1,2}$ \\ Wei-Sheng Chong' \\ 'Department of Dermatology, \\ National Skin Centre, ${ }^{2}$ Lee Kong \\ Chian School of Medicine, Nanyang \\ Technologicial University, Singapore
}

Correspondence: Wei-Sheng Chong

National Skin Centre, I Mandalay Road,

Singapore 308205

Tel +6562534455

Fax +65 62533225

Email wschong@nsc.com.sg

\begin{abstract}
Confluent and reticulated papillomatosis (CRP) of Gougerot and Carteaud was first typified in 1927. With the help of electron microscopy, it has been elucidated that CRP arises due to aberrant keratinization. However, till date, there is no clear consensus on the etiologic trigger for CRP. Prevailing postulates include a bacterial trigger by Dietzia papillomatosis (type strain $\mathrm{N} 1280^{\mathrm{T}}$ ), an exaggerated cutaneous response to Malassezia furfur, an endocrine basis stemming from insulin resistance, ultraviolet light-induced epidermal change, amyloid deposition, and a loss-of-function mutation in keratin 16. CRP typically presents as asymptomatic hyperpigmented papules and plaques with peripheral reticulation over the nape, axillae, upper chest, and upper back, occasionally with extension superior to the forehead and inferior to the pubic region. Dermoscopy may be used in the evaluation of CRP, but its diagnosis is made on clinical grounds given its nonspecific histopathological findings. Although successful treatment with topical keratolytics, retinoids, or antifungals has been reported, antibiotics, such as minocycline, at anti-inflammatory doses have emerged as a preferred therapeutic option. In this article, we review the diagnostic considerations in CRP and its therapeutic options.
\end{abstract}

Keywords: Gougerot, Carteaud, reticulate, papillomatous, diagnosis, treatment

\section{Introduction}

Confluent and reticulated papillomatosis (CRP) was first described in 1927 by Gougerot and Carteaud, ${ }^{1}$ who named this entity as papillomatose pigmentée innominée. They presented further cases and subsequently renamed the condition papillomatose pigmentée confluente et réticulée in $1932 .^{2}$ After 5 years, Wise and Sachs ${ }^{3}$ furnished the first account of CRP in the American literature and the term CRP was coined. ${ }^{4}$

In the earlier decades after its initial description, there was a contention that CRP was a variant of acanthosis nigricans (AN). ${ }^{5,6}$ However, as reports characterizing the condition began to surface from all over the world, CRP was gradually recognized as an uncommon but distinct dermatosis. ${ }^{7}$ It has since also been referred to as the Gougerot-Carteaud syndrome and CRP of Gougerot and Carteaud.

\section{Pathogenesis}

Pathogenetically, CRP is a disease of the epidermis caused due to disordered keratinization, ${ }^{8}$ given its histological features and response to keratolytics and retinoids. Electron microscopy ${ }^{9}$ of lesional skin tissue revealed findings consistent with altered keratinocyte differentiation, namely, 1) altered cornified cellular architecture with snake-coil or triangular stacks and 2) proliferation of lamellar granules (Odland bodies) 
in the stratum granulosa. These findings, in particular the latter, explain the clinical features of CRP (Clinical features section) - secretory lipids produced by lamellar granules are important in mediating corneocyte adhesion and assembly ${ }^{10}$ and are similarly found in greater density in other diseases of epidermal hyperproliferation such as psoriasis. ${ }^{11}$ Augmented levels of involucrin have also been found in lesions of CRP, supporting the concept of keratinopathy. ${ }^{12,13}$

Ultrastructural studies have also shed light on the cause of the tan brown hyperpigmentation seen in $\mathrm{CRP},{ }^{9}$ which is due to the increased melanosomes within the hyperkeratotic stratum corneum. In contrast, dyspigmentation seen in other types of papillomatoses, such as AN, arises from increased melanogenesis. This further delineates CRP as a unique condition in itself. ${ }^{14}$

\section{Etiology}

In the first 5 decades, the prevailing concept was that CRP was due to an abnormal host response to Malassezia furfur. ${ }^{15-17}$ However, as more authors reported inconsistent detection of Malassezia spp. on skin mycological examination in CRP, this theory began to fall out of favor. Indeed, in cases that initially found Malassezia spp. on lesional areas of CRP, fungal clearance (as evidenced by repeated skin scrapings) with antifungal therapy did not result in changes in the cutaneous features. ${ }^{18}$ In cases of detection of fungal organisms, there may also be misdiagnoses of tinea versicolor as CRP.

To date, the most convincing etiological theory in CRP is a bacterial one. Although it had become increasingly recognized that CRP responded readily to a variety of antibiotics (Treatment section), it was not until 2005 when Natarajan et $\mathrm{al}^{19}$ isolated a novel actinomycete resembling Rhodococcus from the skin scrapings in a 17-year-old male with CRP, after 72 hours of incubation at $37^{\circ} \mathrm{C}$ in $5 \%$ carbon dioxide. In 2008 , Jones et $\mathrm{al}^{20}$ expanded on this work in which they isolated and identified an actinomycete from an immunocompetent patient with CRP. Dietzia papillomatosis (type strain $\mathrm{N} 1280^{\mathrm{T}}$ ), an aerobic, Gram-positive, nonmotile, nonsporulating, nonacid-alcohol-fast actinomycete, was identified using a polyphasic taxonomic approach and confirmed to be genotypically and phenotypically distinct from other Dietzia spp. This has since been the main infectious cause that has been potentially implicated in the development of CRP.

CRP has also been proposed to arise in association with endocrinopathies. Cases of individuals with concomitant AN and CRP on a background of conditions fundamentally involving insulin resistance, such as obesity and diabetes mellitus, have been reported. 7,21,22 In these cases, corresponding improvement and worsening of dermatoses with changes in weight and glycemic control corroborate this hypothesis. The possible mechanism is that increased circulating insulin levels in the serum bind to insulin-like growth factor 1, tyrosine kinase, epidermal growth factor, and fibroblast growth factor receptor superfamilies, which are in turn mitogens for epidermal proliferation and reduced apoptosis. ${ }^{23}$ However, since a majority of patients with CRP are healthy with no association with obesity, this theory becomes unattractive. A case of polycystic ovary syndrome (PCOS) presenting with CRP with successful treatment with drospirenone-containing contraceptives has also been reported. ${ }^{24}$ Nonetheless, as patients with PCOS have insulin resistance and a higher incidence of AN that may mimic CRP, it is unlikely that hyperandrogenism, in itself, is responsible for the development of CRP. Hyperthyroidism has also been diagnosed at the same time with a case of CRP, although no postulation was made linking both conditions. ${ }^{25}$

Ultraviolet (UV) light has also been implicated in the pathogenesis of CRP. Vassileva et $\mathrm{al}^{26}$ reported a case of a young female who developed histologically confirmed CRP over tanned areas of sun exposure. They proposed that UV-light-induced melanogenesis and transient epidermal hyperplasia resulted in the cutaneous eruption. This finding, however, has not been replicated any further in the literature.

Groh and Schnyder ${ }^{27}$ proposed that CRP can be classified as the nosological entity of biphasic primary localized amyloidosis after detecting the presence of amyloid deposits in the histological specimens of a series of three patients diagnosed with papillomatose pigmentée confluente et réticulée. Similarly, this has not been borne out in any subsequent studies and may represent confusion between the morphological presentation of reticulation in CRP with that of rippling seen in macular amyloidosis. ${ }^{28}$

Cases of familial CRP have been reported. The first account was by Baden ${ }^{29}$ and subsequently by Hulsbergen Henning and de Wit. ${ }^{30}$ The mode of inheritance and details on consanguinity were not mentioned in these articles. Interestingly, Inaloz ${ }^{31}$ detailed the detection of focal-enhanced expression of keratin-16 (K16) in the stratum granulosum with electron microscopy, in a pair of brothers. K16 mutation is associated with diseases manifesting with palmoplantar keratoderma (yet another disorder of keratinocyte hyperproliferation), such as pachyonychia congenita type 1 , which is inherited in an autosomal dominant fashion. More studies are needed to establish the role of K16 mutation in the pathogenesis of CRP. Another genetic basis for CRP was also put forward by Koguchi et $\mathrm{al}^{32}$ with the first case of CRP occurring in a patient with 15q partial tetrasomy, which is a rare chromosomal aberration that displays various patterns of cutaneous dyspigmentation. 


\section{Clinical features \\ Symptomatology and signs}

CRP is largely asymptomatic but has been described to be pruritic in some individuals. It is limited only to the skin with no systemic involvement. It typically manifests as multiple subcentimeter brown to hyperpigmented papules that may coalesce centrally to form plaques while demonstrating reticulation peripherally (Figure 1). The hallmark of these papules is that they exhibit epidermal changes of scaling, hyperkeratosis, or even atrophy. Rarely, these verrucous papules are arranged as a vertically oriented ripple. ${ }^{33,34}$ In Caucasians, CRP presents as an eruption of erythematous scaly papules with rippling or reticulation. ${ }^{28,35}$ Mottling $^{36}$ and xerosis ${ }^{37}$ have both been described to be present concurrently.

With regard to distribution, CRP tends to involve the upper trunk and axillae. Warty papules in the axillae, as with those found in the submammary creases in women, usually adopt a velvety appearance. Over the anterior aspect of the torso, lesions may extend superoinferiorly in a rhomboidal fashion to involve the anterior neck, lower abdomen, and pubic region (Figure 2). Posteriorly, CRP tends to start off congregating over the interscapular area and extend similarly in a rhomboidal pattern cephalocaudally involving the shoulders (resulting in a cape-like appearance), up to the nape of neck and down to the natal cleft. Sometimes, lesions can be

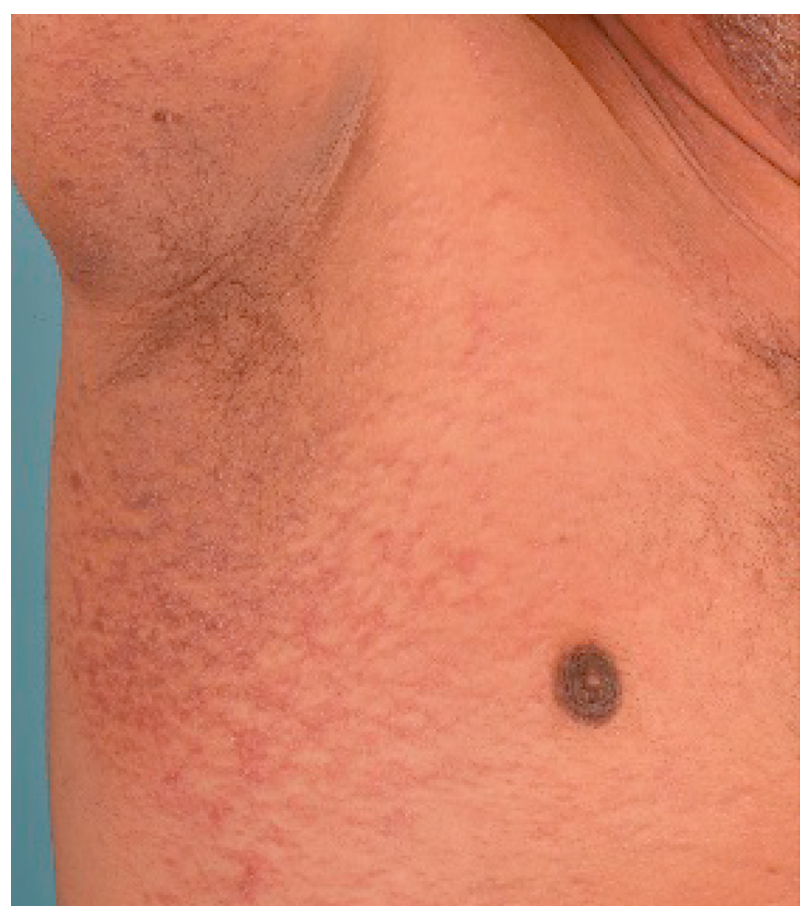

Figure I Coalescent hyperpigmented papules over the axilla with marked reticulation at the peripheries.

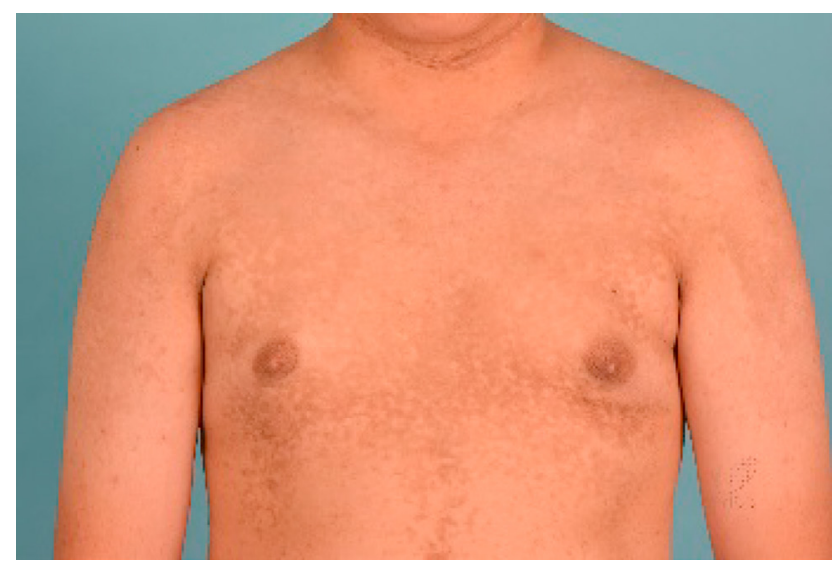

Figure 2 Reticulate hyperpigmentation with fine scaling over anterior chest, shoulders, and upper arms.

seen in the upper limbs including the antecubital fossae and lower limbs including the popliteal fossae..$^{18,38,39}$ An uncommon area of affliction is the forehead. ${ }^{40}$

In CRP, dermoscopic features of brownish pigmentation with overlying white scales and a pattern of "sulci and gyri" have been reported. ${ }^{41}$ The white scale corresponds histologically to basal layer hyperpigmentation, corneal parakeratosis, and compact hyperkeratosis, while the cerebriform pattern was said to be compatible with papillomatosis. This may represent a useful tool in differentiating CRP from other conditions in a simple and rapid fashion.

\section{Demographic data}

CRP is not restricted geographically with cases reported from all over the globe. ${ }^{42}$ However, the epidemiology of CRP varies with race and ethnicity. CRP occurs in higher frequencies in Caucasians. ${ }^{18,43}$ In the white-predominant population, as in a retrospective review from the Mayo Clinic, ${ }^{18}$ the mean age of incidence of CRP was 15 years, with a range of 8-32 years. There was a greater male preponderance with a ratio of $1.4: 1{ }^{43}$ These findings were replicated in a Japanese study in which the mean age of onset was 17 years (range 3-30 years), along with a slight predilection in males. ${ }^{43}$ However, in our study in Singapore, the mean age of onset was 29 years (range 16-55), with a male-to-female ratio of 2.6:1. ${ }^{37} \mathrm{In}$ our study, CRP was found to occur more commonly in Indians, compared with Chinese, Malays, and Caucasians. ${ }^{37}$

\section{Histology}

The archetypal histopathological characteristics of CRP include: 1) undulating basket-weave hyperkeratosis, 2) papillomatosis, 3) focal acanthosis limited to the areas of rete ridge elongation, and 4) increased basal melanin pigmentation. It 
has been suggested that papillomatosis may not be present in early CRP. ${ }^{44}$ The same authors also reported that a helpful diagnostic feature would be the invagination of basket-weave hyperkeratosis into the epidermis, should it be present. ${ }^{44}$ Although the classic findings of CRP may be similar to that of AN, the presence of a superficial perivascular lymphocytic infiltrate around mildly dilated blood vessels coupled with beading of the elastic fibers is unique to $\mathrm{CRP} .{ }^{28}$ Of note, bacterial elements have not been identified in specimens. ${ }^{43}$

\section{Diagnosis}

The diagnosis of CRP is made largely on a clinical basis; the role of histopathology remains as an important means to exclude other dermatoses (Differential diagnoses section). Davis et $\mathrm{al}^{18}$ proposed a set of criteria for the diagnosis of CRP as follows: 1) clinical findings include scaly brown macules and patches, at least part of which appear reticulated and papillomatous, 2) involvement of the upper trunk and neck, 3) fungal staining of scales is negative for fungus, 4) no response to antifungal treatment, and 5) excellent response to minocycline. Based on our retrospective analysis of local cases of CRP in Singapore, we have found good concordance between the diagnostic criteria set forth and our cases. ${ }^{37}$

\section{Differential diagnoses}

There is a wide array of dermatoses that may resemble CRP. The closest mimic in terms of distribution and appearance is AN. AN cannot be reliably distinguished from CRP based on the presence of increased body habitus or a history of insulin resistance, as these comorbidities may coexist with CRP. Clinical clues more consistent with CRP would be the presence of peripheral reticulation and the absence of mucosal and nail involvement in CRP. Histologically, these two conditions can be distinguished based on the features mentioned earlier.

Other differential diagnoses of CRP can be divided according to its morphological appearance. Reticulated hyperpigmentation without papules or plaques may occur in Dowling-Degos disease, Galli-Galli disease, and dyskeratosis congenita. If the patient complains of pruritus in addition to reticulated hyperpigmentation, prurigo pigmentosa has to be suspected and a diagnosis can be clinched with a skin biopsy revealing lymphocytic infiltrate with multiple necrotic keratinocytes.

If a patient presents with dirt-like, slightly verrucous plaques that are resistant to ordinary cleansing over the distribution of CRP, terra firma-forme dermatosis should be considered. Swabbing these lesions with 70\% alcohol would remove the lesions to a large extent and can be a bedside method to differentiate this from CRP. ${ }^{45}$
Uncommon variants of CRP include CRP without pigmentary changes. In such a case, Darier disease is a differential diagnosis. Darier disease presents classically over seborrheic areas and may manifest in the same distribution as CRP. Palmoplantar pits and nail changes, such as bluered striations and distal $\mathrm{V}$-shaped nicking, may be present in the former.

\section{Treatment}

A plethora of options on treatment of CRP is available in the literature. Among the myriad of therapies, minocycline and azithromycin were reported to yield good results.

\section{Antimicrobials}

This section is largely divided into the antibiotic and antifungal therapeutic options.

\section{Antibiotics}

Carteaud $^{46}$ published the initial therapeutic effectiveness of minocycline in CRP in 1965. In the largest prospective cohort $^{47}$ of eleven patients with CRP treated with oral minocycline $50 \mathrm{mg}$ twice a day for 6 weeks with a mean follow-up period of 11 months, nine subjects had close to complete clinical resolution. None of the cases developed side effects. Three cases had relapse of their disease but all improved with reinitiation of minocycline at the same dose. The effectiveness of minocycline was mirrored in retrospective studies conducted in the US ${ }^{18}$ and Singapore. ${ }^{37}$ In the former study, 14 of 18 cases achieved $100 \%$ clearance, whereas four had $>50 \%$ clearance. In the latter, all eleven patients achieved $>50 \%$ clearance. In fact, successful treatment response to minocycline has been proposed as a diagnostic criterion of CRP by Davis et al. ${ }^{18}$ Oral doxycycline ${ }^{48}$ and tetracycline ${ }^{28,49}$ have also been reported to be effective with an absence of recurrence.

The use of minocycline as first-line therapy may be met with concerns of toxicity, such as drug-induced hypersensitivity syndrome, drug-induced lupus, dyspigmentation, and vestibular toxicity. The risk for adverse drug effects may be mitigated by close follow-up. However, minocycline is not recommended in pregnancy (US Food and Drug Administration Category D), ${ }^{28}$ and an alternative will be required. Azithromycin, though not as extensively reported as minocycline, has emerged to be an efficacious option. Oral azithromycin taken at doses of $500 \mathrm{mg}$ once a day for a week in two reports ${ }^{48,50}$ and $500 \mathrm{mg}$ three times a week for 3 weeks in another report ${ }^{51}$ had resulted in complete clearance of lesions with no recurrence in 6 months. 
Oral clarithromycin at $500 \mathrm{mg}$ once a day for 5 weeks and erythromycin 1,000 mg daily for 6 weeks have also been reported to be effective. ${ }^{51}$ There was one case report of CRP resistant to treatment with erythromycin that resolved with minocycline..$^{40}$ The authors proposed that macrolides, such as azithromycin, have a much safer side effect profile and are pregnancy category B drugs. Hence, they may represent as a superior option to minocycline in the first-line treatment of CRP. ${ }^{48}$

The antibacterial therapies that have been reported to be efficacious in CRP possess both antibacterial and antiinflammatory properties, ${ }^{28}$ with the exception of fusidic acid, ${ }^{51}$ cefdinir,${ }^{51}$ cloxacillin, ${ }^{52}$ and amoxicillin. ${ }^{53}$ The inhibitory action of the tetracycline group of antibiotics on metalloproteinases, hydrolases, phospholipase A2, TNF- $\alpha$, IL- $1 \beta$, and IL- 6 confers their anti-inflammatory effects, ${ }^{54-57}$ while macrolides result in immunomodulation through suppression of IL-8 and neutrophil oxidative burst. ${ }^{58}$ It appears that these medications may indeed be used for the latter purpose given that they are prescribed at doses where antiinflammatory effects are harnessed. As such, the jury is still out as to whether there may be a true bacterial role in the pathogenesis of CRP, and the role of anti-inflammatory agents in keratinocytic diseases is yet to be delineated.

\section{Antifungals}

The basis of using antifungals in the treatment of CRP stems from the initial hypothesis that CRP arises from M. furfur colonization. Topical selenium sulfide applied daily for 3 weeks and weekly for another 3 weeks attained $80 \%$ clinical resolution in a patient with CRP. ${ }^{59}$ In this case, demonstration of yeast on potassium hydroxide preparation was negative, leaving one to surmise that treatment response may be due to the keratolytic properties of selenium sulfide, rather than its antifungal effect.

Other topical and systemic antifungal therapies, such as ketoconazole, ${ }^{60}$ tolnafate, ${ }^{42}$ and itraconazole,${ }^{61}$ have resulted in positive outcomes. However, recurrences were reported in all these treatments. In addition, there have also been multiple reports of antifungals failing to confer any beneficial outcome. ${ }^{59}$ Moreover, it should be noted that the US Food and Drug Administration has issued a warning against the use of systemic ketoconazole given the risk of fatal fulminant hepatotoxicity. Of note, there has been no consistent correlation between the presence of fungal elements on skin scrapings and response to antifungals. Overall, antifungal treatment remains empiric at best for the treatment of CRP.

\section{Topical therapy}

The use of topical retinoids to reduce keratinocyte proliferation appears intuitive, in view of the pathogenesis of CRP. Topical retinoids, ${ }^{62}$ tazarotene,${ }^{62}$ urea,${ }^{63}$ calcipotriol,,${ }^{64,65}$ and tacrolimus ${ }^{66}$ have all been used successfully. Interestingly, $0.1 \%$ tacrolimus ointment was being used in a case in which relapse occurred after initial response to minocycline, and there was no recurrence 2 months after tacrolimus ointment was stopped. The clinical utility of topical therapy in CRP may be limited by its cumbersome application given that extensive areas are usually involved and areas hard-to-reach in self-application (such as the mid-upper back) are often affected. Topical therapies may therefore be more appropriate for cases with relapse in which limited body areas are involved.

\section{Systemic retinoids}

Systemic retinoids, such as isotretinoin (both low ${ }^{67}$ and high dose $^{68,69}$ regimens) and etretinate,,$^{70}$ have achieved positive outcomes in CRP. However, given the superior safety profile of minocycline and azithromycin, systemic retinoids are typically reserved for nonresponders to antibiotics. ${ }^{28}$

\section{Prognosis}

The prognosis of CRP is good with marked response $(>50 \%$ improvement) when minocycline or azithromycin is used as first-line treatment. ${ }^{18,37}$ Sustained clinical remission after a follow-up period of up to 24 months has been reported. ${ }^{49}$ Recurrences are uncommon and have been reported largely in those treated with nonantibacterial therapies..$^{49}$ Recurrence rates are in the range of $13.8 \%{ }^{37}$ to $15.4 \%{ }^{18}$ In such cases, either treatment with minocycline or doxycycline or repeating the initial course of effective antibiotics produces high rates of subsequent remission. . $^{18,37,49}$

Of note, two cases of spontaneous resolution of CRP without any treatment have been reported. ${ }^{18,71}$ The time to achieving resolution ranges from 12 months to 39 months. However, opting for conservative management in patients in CRP is largely limited by the cosmetic distress it causes.

\section{Conclusion}

CRP is an uncommon and treatable keratinizing disorder predominantly afflicting adolescents and young adults. There have been many hypotheses of its etiology but its pathogenesis is still not well-defined. Its diagnosis is predominantly clinical, supported by consistent histological features. 


\section{Disclosure}

Doctors Wei-Sheng Chong, Hong Liang Tey, and Joel Hua-Liang Lim had full access to all of the data in the study and take responsibility for the integrity of the data and the accuracy of the data analysis. The authors report no conflicts of interest in this work.

\section{References}

1. Gougerot H, Carteaud A. Papillomatose pigmentée innominée [Unclassified pigmented papillomatosis]. Cas pour diagnostic. Bulletin de la Société française de dermatologie et de syphiligraphie. 1927;34:712-719.

2. Gougerot H, Carteaud A. Neue Formen der papillomatose [New forms of papillomatosis]. Archiv für Dermatologie und Syphilis. 1932;165:232-267.

3. Wise F, Sachs W. Cutaneous papillomatose: papilllmotose confluente et réticulée. Arch Dermatol Syphilol. 1937;36:475-485.

4. Wise F. Confluent and reticular papillomatosis (Gougerot-Carteaud). Arch Dermatol Syphilol. 1937;35:550.

5. Decroix J, Bourlond A, Minet A, Eggers S. Gougerot-Carteaud confluent and reticulated papillomatosis associated with pseudoacanthosis nigricans: the same entity? Ann Dermatol Venereol. 1987;114(2):223-226.

6. Kesten BM, Jarnes HD. Pseudoatrophoderma colli, acanthosis nigricans and confluent and reticular papillomatosis. Arch Dermatol. 1957;75(4):525-542.

7. Hamilton D, Tavafoghi V, Shafer JC, Hambrick GW Jr. Confluent and reticulated papillomatosis of Gougerot and Carteaud: its relation to other papillomatoses. J Am Acad Dermatol. 1980;2(5):401-410.

8. Miescher VG. Erythrokeratodermia papularis et reticularis [Papillary and reticular erythrokeratoderma]. Dermatologica. 1954;108(4-6):303-309.

9. Jimbow M, Talpash O, Jimbow K. Confluent and reticulated papillomatosis: clinical, light and electron microscopic studies. Int J Dermatol. 1992;31(7):480-483.

10. Elias PM. Epidermal lipids, barrier function, and desquamation. J Invest Dermatol. 1983;80(1 Suppl):44s-49s.

11. Zech H, Lagerholm B, von Weittstein D. Particles resembling virus in psoriatic lesions. Virology. 1961;14:489.

12. Kanitakis J, Zambruno G, Viac J. Involucrin expression in keratinisation disorders of the skin: a preliminary study. $\mathrm{Br} J$ Dermatol. 1987;117(4):479-486.

13. Gupta AK, Bara R, Bluhm R, et al. Skin diseases with Malasezzia species. J Am Acad Dermatol. 2004;51(5):785-798.

14. Jimbow M, Jimhow K. Pigmentary disorders in oriental skin. Clin Dermatol. 1989;7(2):11-27.

15. Roberts SOB, Lachapelle JM. Confluent and reticulate papillomatosis (Gougerot-Carteaud) and Pityrosporum orbiculare. Br J Dermatol. 1969;81(11):841-845.

16. Yesudian P, Kamalam S, Razack A. Confluent and reticulated papillomatosis (Gougerot-Carteaud). Acta Derm Venereol (Stockh). 1973;53(5):381-384.

17. Kellet JK, Macdonald RH. Confluent and reticulated papillomatosis. Arch Dermatol. 1985;121(5):587-588.

18. Davis MDP, Weenig RH, Camilleri MJ. Confluent and reticulated papillomatosis (Gougerot-Carteaud syndrome): a minocycline-responsive dermatosis without evidence for yeast in pathogenesis. A study of 39 patients and a proposal of diagnostic criteria. $\mathrm{Br} J$ Dermatol. 2006;154(2):287-293.

19. Natarajan S, Milne D, Jones AL, Goodfellow M, Perry J, Koerner RJ. Dietzia strain X: a newly described actinomycete isolated from confluent and reticulate papillomatosis. Br J Dermatol. 2005;153(4): 825-827.

20. Jones AL, Koerner RJ, Natarajan S, Perry JD, Goodfellow M. Dietziapapillomatosis sp. nov., a novel actinomycete isolated from the skin of an immunocompetent patient with confluent and reticulated papillomatosis. Int J Syst Evol Microbiol. 2008;58(Pt 1):68-72.
21. Lim KB. Confluent and reticulated papillomatosis. Cutis. 1988;41: 215-217.

22. Hirokawa M, Matsumoto M, Iizuka H. Confluent and reticulated papillomatosis: a case with concurrent acanthosis nigricans associated with obesity and insulin resistance. Dermatology. 1994;188(2):148-151.

23. Cannavo SP, Guarneri P, Borgia F, Guarneri B. Confluent and reticulated papillomatosis and acanthosis nigricans in an obese girl: two distinct pathologies with a common pathogenetic pathway or a unique entity dependent on insulin resistance? JEADV. 2006;20(4):478-479.

24. Ozdemir S, Ozdemir M, Toy M. Confluent and reticulated papillomatosis associated with polycystic ovary syndrome treated with a combined contraceptive containing drospirenone. JEADV. 2009;23(3): 358-359.

25. Zhang $\mathrm{CH}$, Zhang $\mathrm{C}$, Wu J, et al. Confluent and reticulated papillomatosis associated with hyperthyroidism. Eur J Dermatol. 2010;20(6): 833-835.

26. Vassileva S, Pramatarov K, Popova L. Ultraviolet light-induced confluent an reticulated papillomatosis. J Am Acad Dermatol. 1989;21(2 Pt 2):413-414.

27. Groh V, Schnyder UW. Nosology of confluent and reticulated papillomatosis (Gougerot-Carteaud). Hautarzt. 1983;32(2):81-86.

28. Schienfeld N. Confluent and reticulated papillomatosis: a review of the literature. Am J Clin Dermatol. 2006;7(5):305-313.

29. Baden HP. Familial cutaneous papillomatosis. Arch Dermatol. 1965;92(4):394-395.

30. Hulsbergen Henning JP, de Wit RF. Familial occurrence of confluent and reticulated papillomatosis. Arch Dermatol. 1981;117(12):809-810.

31. Inaloz HS. Familial confluent and reticulated papillomatosis. Arch Dermatol. 2002;138(2):276-277.

32. Koguchi H, Ujiie H, Aoyagi S, Osawa R, Shimuzu H. Confluent and reticulated papillomatosis associated with $15 \mathrm{q}$ tetrasomy syndrome. Acta Derm Venereol. 2013;93(2):202-203.

33. Min ZS, Tan C, Xu P, Zhu WY. Confluent and reticulated papillomatosis manifested as vertically rippled and keratotic plaques. Postepy Dermatol Alergol. 2014;31(5):335-337.

34. Hudacek KD, Haque MS, Hochberg AL, Cusack CA, Chung CL. An unusual variant of confluent and reticulated papillomatosis masquerading as tinea versicolor. Arch Dermatol. 2012;148(4):505-508.

35. Basak PY, Baysal V, Ozcanli C. Confluent and reticulated papillomatosis: failure of response to calcipotriol and coincidental association with vascular mottling. JEADV. 2001;15(6):591-592.

36. Thomsen K. Confluent and reticulated papillomatosis (GougerotCarteaud). Acta Derm Venereol Suppl (Stockh). 1979;59(85):185-187.

37. Huang W, Ong G, Chong W. Clinicopathological and diagnostic characterisation of confluent and reticulated papillomatosis of Gougerot and Carteaud: a retrospective study in a southeast-asian population. Am J Clin Dermatol. 2015;16(2):131-136.

38. Lee D, Cho K, Hong S, Seo J, Hwang S, Sung H. Two cases of confluent and reticulated papillomatosis with an unusual location. Acta Derm Venereol. 2009;89(1):84-65.

39. Treat JR, Barak OG, James WD. Nonpigmenting confluent and reticulated papillomatosis. Pediatr Dermatol. 2006;23(5):497-499.

40. Kim BS, Lim HJ, Kim HY, Lee WJ, Lee SJ, Kim do W. Case of minocycline-effective confluent and reticulated papillomatosis with unusual location on forehead. J Dermatol. 2009;36(4):251-253.

41. Bernardes Filho F, Quaresma MV, Rezende FC, Kac BK, Nery JA, Azulay-Abulafia L. Confluent and reticulate papillomatosis of Gougerot-Carteaud and obesity: dermoscopic findings. An Bras Dermatol. 2014;89(3):507-509.

42. Kumar AS, Pandhi RK. Syndrome of Carteaud and Gougerot - case report. Confluent and reticulate papillomatosis. Mykosen. 1984;27(6): 313-315.

43. Schwartz RA [webpage on the Internet]. Confluent and Reticulated Papillomatosis [online]. Available from: http://emedicine.medscape. com/article/1106748-overview.

44. Atasoy $\mathrm{M}$, Aliağaoğlu $\mathrm{C}$. Is confluent and reticulated papillomatosis without papillomatosis early or late stage of confluent and reticulated papillomatosis? J Cutan Pathol. 2006;33(suppl 2):52-54. 
45. Akkash L, Badran D, Al-Omari AQ. Terra Firma forme dermatosis. Case series and review of the literature. J Dtsch Dermatol Ges. 2009; 7(2):102-107.

46. Carteaud A. A case of Gougerot and Carteaud's confluent and reticulated papillomatosis, completely cleared up by antibiotics. Bull Soc Fr Dermatol Syphiligr. 1965;72(4):396-397.

47. Montemarano AD, Hengge M, Sau P, Welch M. Confluent and reticulated papillomatosis: response to minocycline. J Am Acad Dermatol. 1996;34(2 Pt 1):253-256.

48. Gruber E, Zamolo G, Saftic M, Peharda V, Kastelan M. Treatment of confluent and reticulated papillomatosis with azithromycin. Clin Exp Dermatol. 1998;23(4):191.

49. Angeli-Besson C, Koeppel MC, Acquet PJ, Andrac L, Sayag J. Confluent and reticulated papilomatosis (Gourgerot-Carteaud) treated with tetracyclines. Int J Dermatol. 1995;34(8):567-569.

50. Atasoy M, Ozdemir S, Aktaş A, Aliağaoğlu C, Karakuzu A, Erdem T. Treatment of confluent and reticulated papillomatosis with azithromycin. J Dermatol. 2004;31(8):682-686.

51. Jang HS, Oh CK, Cha JH, Cho SH, Kwon KS. Six cases of confluent and reticulated papillomatosis alleviated by various antibiotics. $\mathrm{J} \mathrm{Am}$ Acad Dermatol. 2001;44(4):652-655.

52. Yamamoto A, Okubo Y, Oshima H, Oh-i T, Koga M. Two cases of confluent and reticulate papillomatosis: successful treatments of one case with cefdinir and another with minocycline. J Dermatol. 2000;27(9): 598-603.

53. Davis RF, Harman KE. Confluent and reticulated papillomatosis successfully treated with amoxicillin. Br J Dermatol. 2007;156(3): 583-584.

54. Bahrami F, Morris DL, Pourgholami MH. Tetracyclines: drugs with huge therapeutic potential. Mini Rev Med Chem. 2012;12(1):44-52.

55. Sapadin AN, Fleischmajer R. Tetracyclines: nonantibiotic properties and their clinical implications. J Am Acad Dermatol. 2006;54(2): 258-265.

56. Dormn G, Cseh S, Hajd I, et al. Matrix metalloproteinase inhibitors: a critical appraisal of design principles and proposed therapeutic utility. Drugs. 2010;70(8):949-964.

57. Meyer-Hoffert U. Reddish, scaly, and itchy: how proteases and their inhibitors contribute to inflammatory skin diseases. Arch Immunol Ther Ex. 2009;57(5):345-354.
58. Amsden GW. Anti-inflammatory effects of macrolides - an underappreciated benefit in the treatment of community-acquired respiratory tract infections and chronic inflammatory pulmonary conditions. J Antimicrob Chemother. 2005;55:10-21.

59. Nordby CA, Mitchell AJ. Confluent and reticulated papillomatosis responsive to selenium sulfide. Int J Dermatol. 1986;25(3):194-199.

60. Hamguchi T, Nagase M, Higuchi R, Takiuchi I. A case of confluent and reticulated papillomatosis responsive to ketoconazole cream. Nihon Ishinkin Gakkai Zasshi. 2002;43(2):95-98.

61. Shimizu S, Han-Yaku H. Confluent and reticulated papillomatosis responsive to minocycline. Dermatology. 1997;194(1):59-61.

62. Kagi MK, Trueb R, Wuthrich B, Burg G. Confluent and reticulated papillomatosis associated with atopy. Successful treatment with topical urea and tretinoin. Br J Dermatol. 1996;134(2):381-382.

63. Bowman PH, Davis LS. Confluent and reticulated papillomatosis: response to tazarotene. JAm Acad Dermatol. 2003;48(5 suppl):S80-S581.

64. Gulec AT, Seckin D. Confluent and reticulated papillomatosis: treatment with topical calcipotriol. Br J Dermatol. 1999;141(6):1150-1151.

65. Kurkeuoglu N, Celebi CR. Confluent and reticulated papillomatosis: response to topical calcipotriol. Dermatol. 1995;191(4):341-342.

66. Tirado-Sánchez A, Ponce-Olivera RM. Tacrolimus in confluent and reticulated papillomatosis of Gougerot Carteaud. Int J Dermatol. 2013;52(4):513-514.

67. Lee MP, Stiller MJ, McClain SA, Shupack JL, Cohen DE. Confluent and reticulated papillomatosis: response to high-dose oral isotretinoin therapy and reassessment of epidemiologic data. J Am Acad Dermatol. 1994;31(2 pt 2):327-331.

68. Hodge JA, Ray MC. Confluent and reticulated papillomatosis: response to isotretinoin. J Am Acad Dermatol. 1991;24(4):654.

69. Solomon BA, Laude TA. Two patients with confluent and reticulated papillomatosis: response to oral isotretinoin and $10 \%$ lactic acid lotion. J Am Acad Dermatol. 1996;35(4):645-646.

70. Bruynzeel-Koomen CA, de Wit RF. Confluent and reticulated papillomatosis successsfully treated with the aromatic etretinate. Arch Dermatol. 1984;120(9):1236-1237.

71. Sakiyama T, Amagai M, Ohyama M. Chronology of confluent and reticulated papillomatosis: spontaneous regression in a case after longterm follow-up may imply transient nature of the condition. J Dermatol. $2015 ; 42(3): 335-336$.
Clinical, Cosmetic and Investigational Dermatology

\section{Publish your work in this journal}

Clinical, Cosmetic and Investigational Dermatology is an international, peer-reviewed, open access, online journal that focuses on the latest clinical and experimental research in all aspects of skin disease and cosmetic interventions. This journal is included on PubMed. The manuscript management system is completely online

\section{Dovepress}

and includes a very quick and fair peer-review system, which is all easy to use. Visit http://www.dovepress.com/testimonials.php to read real quotes from published authors 